Original Research Paper

\title{
Sorption Extraction of Noble and Non-Ferrous Metals from Process Leaching Solutions
}

\author{
Bagdaulet Kenzhalyevich Kenzhaliyev, \\ Renata Ramilevna Iskhakova and Zamzagul Duisenovna Dosymbayeva
}

Kazakh-British Technical University, Almaty, Republic of Kazakhstan

\author{
Article history \\ Received: 06-10-2015 \\ Revised: $12-11-2015$ \\ Accepted: 13-11-2015 \\ Corresponding Author: \\ Bagdaulet Kenzalyevich \\ Kenzhaliyev \\ Kazakh-British Technical \\ University, Almaty, Republic \\ of Kazakhstan \\ Email: kenzhaliyevkz@gmail.com
}

\begin{abstract}
In view of the annual increase in ore processing output for low grade or refractory gold-bearing ores, as well as recoverable raw materials, stricter requirements for completeness of gold extraction and environmental safety, the interest is rising in possible alternatives to substitute the cyanide process used in gold mining practice. One of such alternatives is to convert metals into solutions of various chemical compositions by means of electric current-electrochemical leachingfollowed by metal sorption extraction. This paper deals with the issues of sorption behavior of noble (gold, silver) and non-ferrous (copper, iron, cobalt, zinc, nickel, manganese, lead) metals from thiosulfate solutions for chemical and electrochemical leaching of concentrates of two mineral deposits using various anionites. Factors affecting metal uptake most significantly were determined. Degree of zinc and nickel sorption extraction from electrochemical leaching solutions made $99 \%$. It has been established that the nature of metal sorption extraction from process solutions is connected with the micro structure of leaching solutions having quasi-homogeneous structure.
\end{abstract}

Keywords: Leaching Solutions, Noble Metals, Non-Ferrous Metals, Sorption

\section{Introduction}

The global trend in mineral resources base development lies in increasing the volume of raw mineral sources involved in processing generally by means of lower grade and compositionally complicated deposits. It is possible to increase mineral resources base of gold using low-grade, refractory and man-made raw materials, which may be achieved as a result of efficiency improvement of the processing technology and completeness of valuable component extraction. The most widespread ore refractory behavior factor is caused by gold availability inside sulfide mineral, primarily in pyrite and arsenopyrite, with minimum size of the embedded gold grains ranging from decimicron to centimicron. Among the scientific and technical problems facing modern gold mining industry, the problem of extracting gold, silver and non-ferrous metals from recoverable, man-made and refractory mineral stock may be referred to the most significant ones (Adams, 2005; Vignes, 2013). Wide occurrence of goldbearing ores with ultradispersed inclusions of valuable components in the nature necessitates their large-scale involvement into processing. Complicated multi-stage processing flow sheets for such types of refractory ores prevent from extracting ultradispersed gold completely; therefore in most cases such mineral stock shall remain unprocessable and refers to substandard ores according to the economic and environmental criteria. Commercial development of compositionally complicated ores with low content of gold (1.0-2.0 g/t) using conventional processing technology is accompanied with huge losses of valuable and associated components having grain size less than $40 \mu \mathrm{m}$.

The purpose of the present research is to study sorption of thiosulfate complexes of noble and nonferrous metals from thiosulfate solutions for chemical and electrochemical leaching with various anionexchange resins; to investigate sorption properties of a number of new anion-exchange resins.

\section{Literature Review}

Development of a number of technologies, including heap leaching, enables to involve ores containing about 1 $\mathrm{g} / \mathrm{t}$ of gold in ore processing and achieve its extraction up to $60-80 \%$. However, processing of gold-bearing ores of numerous deposits is restrained by refractory behavior 
factor for the subsequent gold extraction by hydrometallurgical methods. Practically all methods of vein gold processing have considerable disadvantages resulting in technological, economic and environmental problems during their implementation. Complicated processing flow sheets are energy intensive, mainly due to multi-stage additional grinding of products. Presence of arsenopyrite in the majority of ores limits the possibility to process them according to gravity separation and flotation schemes because of strict requirements for flotation concentrate with regard to arsenic content and practically excludes pyrometallurgy.

One of the main ways to increase process efficiency of the noble and non-ferrous metals extraction from refractory ore is improvement of modern hydrometallurgical processes with appropriate efficient methods of metal extraction from solutions. Currently the primary way to build up competitiveness and profitability of noble and non-ferrous metals production is to combine conventional technology with innovative ones: Heap and electrosorption leaching, electrochemical extraction, hydrometallurgical solution processing, etc. In addition, due to increasing range of application of nonferrous, rare and precious metals stricter requirements are imposed on their purity. Production of pure metals is complicated by the fact that because of the high-grade ore lack metallurgical recovery practice involves natural raw materials containing negligible amount of valuable components (1-3 g per $1 \mathrm{t}$ of ore and even less) (Lorenzen and Van Deventer, 2003). In many cases the existing pyro- and hydrometallurgical methods fail to ensure the required purity of the product extracted from such raw materials, as well as comprehensive extraction of valuable substances from polymetallic ores and concentrates (Bringas and Wayman, 1998; Su, 2012).

Cyanide process widely used both in the domestic and foreign industry is the basis of modern metallurgy of gold (Syed, 2012). Environmental aspects arising in connection with the use of cyanide solvents related to highly toxic substances are becoming increasingly pressing. In addition to the environmental hazard cyanide leaching method has a number of other shortcomings. Thus, to prevent cyanide ion hydrolysis the presence of protective alkalis is required, i.e., maintenance of a high $\mathrm{pH}$-value of solutions, which makes it impossible to apply efficient oxidizers and therefore the process of gold dissolution has a longer duration (above $72 \mathrm{~h}$ ). High tendency of cyanide ion to form complexes with ions of non-ferrous metals leads to additional consumption of reagent and during gold sorption concentrating makes it difficult to selectively remove it from the solution and complicates the regeneration of ion-exchange materials, leading to the loss of the precious metal with the "tailings". This results in the need to seek new ways of leaching processes using less environmentally hazardous solvents (Kyle et al.,
2012). Gold is often associated with sulfides and requires using flotation followed by autoclave or bacterial leaching of concentrates (Xia, 2008). Sulfide ores are difficult to process by conventional methods. According to the research, the intensity of leaching copper and zinc from sulfide ores is commensurable with this factor for mixed and oxidized ores (0.01-0.5\% of copper per day and $0.1-1.0 \%$ of zinc per day, respectively) (Harvey et al., 1992; Lalancette et al., 1999; Conić et al., 2014).

In view of the above it becomes necessary to carry out integrated processing of refractory sulfide gold concentrates and to substitute cyanide with less expensive and less toxic thiosulfate solvent, intensifying the process rate and reducing costs for detoxification of refined products. Hydrometallurgical preparation of sulfide concentrates allows obtaining chemical products, from which gold can be extracted by means of leaching with non-cyanide complex-forming reagents. A number of reagents were offered as a possible alternative to cyanide, including thiosulfates, thiourea (Yuce, 1994), halides (Tran and Davis, 1992), polysulfides (Luo et al., 2006) and thiocyanates (Akcil et al., 2015). The greatest interest in the global practice of gold extraction from natural materials is generated by the leaching process where ammonium or sodium thiosulfate is used as the main reagent (Grosse et al., 2003; Zhang and Dreisinger, 2003; Petersen and Muzawazi, 2014; Lampinen et al., 2015), since precisely this method is acquiring practical importance for the conditions of the in-situ leaching. Thiosulfate leaching possesses obvious advantages, both in terms of technological and environmental parameters (Wan, 1997; West-Sells and Hackl, 2005).

The thiosulfate leaching process is based on oxidation of gold and silver with atmospheric oxygen over thiosulfate in acidic medium:

$$
\begin{aligned}
& 4 \mathrm{Au}+8 \mathrm{~S}_{2} \mathrm{O}_{3}{ }^{2-}+\mathrm{O}_{2}+4 \mathrm{H}^{+} \rightarrow 4\left[\mathrm{Au}\left(\mathrm{S}_{2} \mathrm{O}_{3}\right)_{2}\right]^{3-}+2 \mathrm{H}_{2} \mathrm{O} \\
& 4 \mathrm{Ag}+8 \mathrm{~S}_{2} \mathrm{O}_{3}{ }^{2-}+\mathrm{O}_{2}+4 \mathrm{H}^{+} \rightarrow 4\left[\mathrm{Ag}\left(\mathrm{S}_{2} \mathrm{O}_{3}\right)_{2}\right]^{3-}+2 \mathrm{H}_{2} \mathrm{O}
\end{aligned}
$$

Accordingly, there is a number of patents on thiosulfate leaching of crude ore (Wan et al., 1995; Choi et al., 2009). Depending on the $\mathrm{pH}$ of the medium, thiosulfate may be unstable and converted to polythionates. US Patent of 1976 is interesting in this regard, where, in contrast to many others, alkaline ammonia solution rather than acid one was offered for ore uncovering (Dubeck and Im, 1976).

Formed thiosulfate gold complex is very strong (dissociation constant is equal to $10^{-26}$ ). The presence of soluble copper and sulfides can slow down the process of thiosulfate dissolution of gold, if special measures are not taken. In particular, it is recommended to carry out the process in a weak oxidizing medium. 
Thiosulfate leaching is applicable to the ores being persistent to the cyanide process: Manganese and copper-bearing ones. The optimal conditions shall be preserved maintaining $\mathrm{pH}$-value at the level of 7-8 units in the solution. This ensures the stability of thiosulfate ions. In their absence, gold extraction sharply decreases, in addition, to increase the reaction rate it is recommended to enter elemental sulfur in the system.

Sorption on synthetic ion exchange materials is one of the most advanced methods for the hydrometallurgical extraction and concentration of noble and non-ferrous metals (Mohammadnejad et al., 2011; Kononova et al., 2014). For several decades a number of businesses have already been operating in the domestic industry using ion exchange resin sorption process both from the solutions and directly from ore slurries. The issues of ion exchanger regeneration and metal deposition from the resulting column effluents are addressed successfully. Experience gained has shown great prospects of the sorption technology.

Currently application of sorption method for noble and non-ferrous metals extraction from thiosulfate solutions is of utmost interest; this method allows increasing total extraction of noble metals from complex raw materials and prevents generation of toxic waste polluting the environment. Here the greatest difficulty is presented by selective metal extraction, which is complicated by the influence of impurity metals. In this regard, investigation into the selection of ion-exchange resins being able to selectively extract the target metals is an urgent task.

The range of sorbents showing capacity for ion exchange and donor-acceptor interactions and recommended for extraction of noble and non-ferrous metals from solutions is rather wide. However, absence of selective ion-exchange resins for gold extraction highly complicates the technology of its production. Investigated by the authors strong-base anion-exchange resins (AB-17, AM, IRA-400), having high sorption capacity and anion exchange ability in acidic and alkaline media, fail to meet requirements for selectivity of noble metal ions extraction. Quite a number of works are devoted to extraction of noble metals from chloride (Laatikainen and Paatero, 2005; Aktas and Morcali, 2011), thiocyanate (Li et al., 2012; Kononova et al., 2007) and thiosulfate (Fotoohi and Mercier, 2015) solutions using various sorbents.

\section{Materials and Methods}

While investigating sorption processes of non-ferrous (copper, iron, cobalt, zinc, nickel, manganese, lead) and noble (gold, silver) metals, chemical and electrochemical leaching solutions of concentrates from " $\mathrm{A}$ " and "M" deposits were used. Sodium thiosulfate solution was applied as a solvent. A composite sulfur-graphite electrode was used as a source of leaching agent during preparation of electrochemical leaching solutions and it simultaneously ensured electrochemical reactions in the electrode-solution-mineral stock system (Kenzhaliev, 2014; Kenzhaliev et al., 2014). New anion-exchange resins were used as sorbents: AV-16 strong-base anionite, BNA-1medium-base anionite, Purolite A500U/4994 and also AM-2B. Sodium thiosulfate having concentration of $0.2 \mathrm{M}$ was used as a solvent. The experiments were carried out by stirring at a rate of $500 \mathrm{rpm}$, with anionite-to-solutions volume ratio of 1:500 and temperature $25^{\circ} \mathrm{C}$.

Compositions of leaching solutions were determined using ContrAA 300 Flame Atomic Absorption Spectrometer. Spectra of leaching solutions in the ion form were obtained at Avatar 370 FT-IR Fourier Tranform InfraRed Spectrometer in the spectral range $4000-400 \mathrm{~cm}^{-1}$ from the capillary layers in windows of KRS-5. Spectra were recorded from the layers with transmittance of $13-14 \%$ at a frequency of $1651 \mathrm{~cm}^{-1}$.

\section{Results}

\section{Sorption of Noble and Non-Ferrous Metals from Chemical Leaching Process Solutions}

The findings of the investigations of metal sorption extraction from chemical leaching solutions of " $\mathrm{A}$ " deposit concentrate is shown in the Fig. 1.

As a result of studying metal sorption extraction process from leaching solutions of "M" deposit concentrate using sodium thiosulfate as a solvent and AV-16, BNA-1, AM-2B and Purolite A500U/4994 anionites (Fig. 2), it was revealed that the degree of $\mathrm{Mn}$ sorption by $\mathrm{AB}-16$ anionite made $50 \%$ and sorption degree of other metals did not exceed $20 \%$ (Fig. 2 a).

The degree of metal sorption extraction from the chemical leaching solution of "M" deposit concentrate on AM-2B (Fig. 2c) and Purolite A500U/4994 (Fig. $2 \mathrm{~d})$ ion-exchange resins is practically similar.

\section{Sorption of Noble and Non-Ferrous Metals from Electrochemical Leaching Process Solutions}

Degree of metal sorption extraction from electrochemical leaching solution of "A" deposit concentrate is shown in the Fig. 3.

During investigation of metals sorption behavior in the electrochemical leaching solutions of " $A$ " deposit concentrate the best extraction results were obtained for zinc: $85 \%$ on AV-16 anionite (Fig. 3a), 99\% on BNA-1 anionite (Fig. 3b) and practically $100 \%$ on Purolite A500U/4994 anionite (Fig. 3d).

Degree of metal sorption extraction from electrochemical leaching solution of "M" deposit concentrate with anionites is shown in the Fig. 4. 


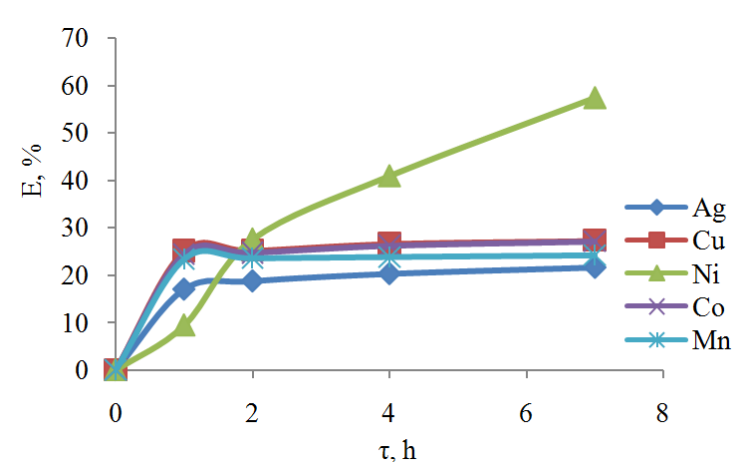

(a)

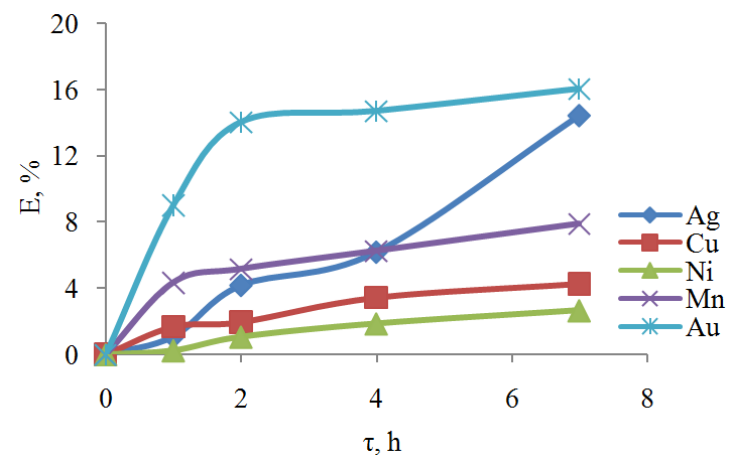

(c)

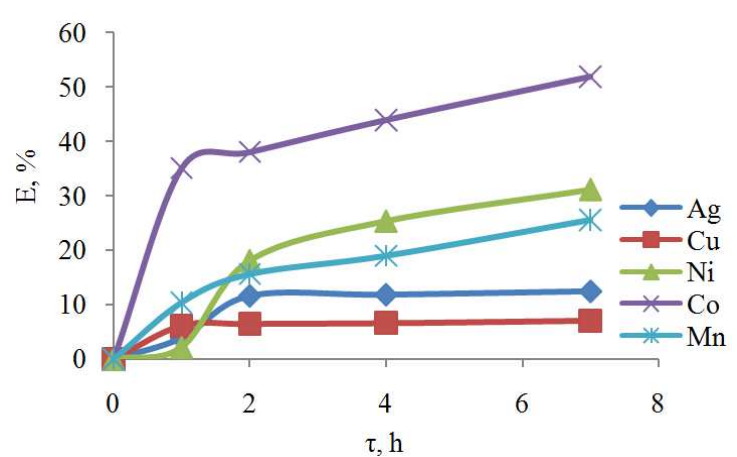

(b)

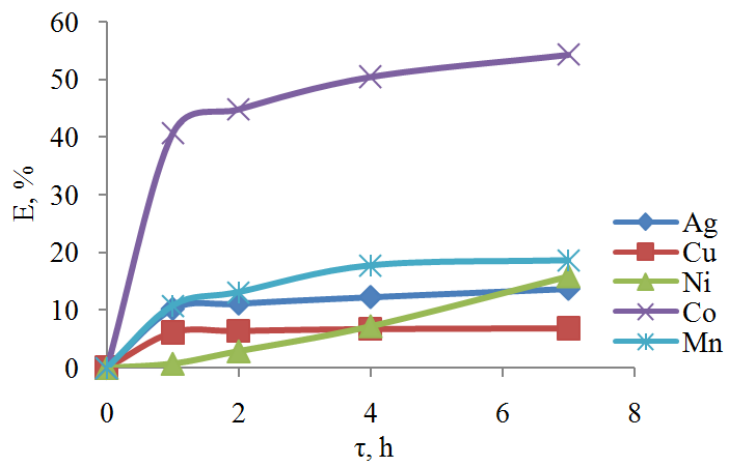

(d)

Fig. 1. (a) AV-16, (b) BNA-1, (c) AM-2B, (d) Purolite A500U/4994, degree of metal sorption extraction from the chemical leaching solution of "A" deposit concentrate with different ion-exchange resins

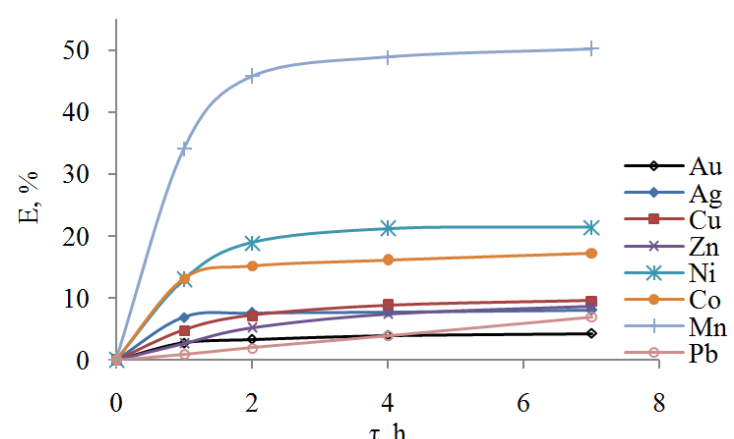

(a)

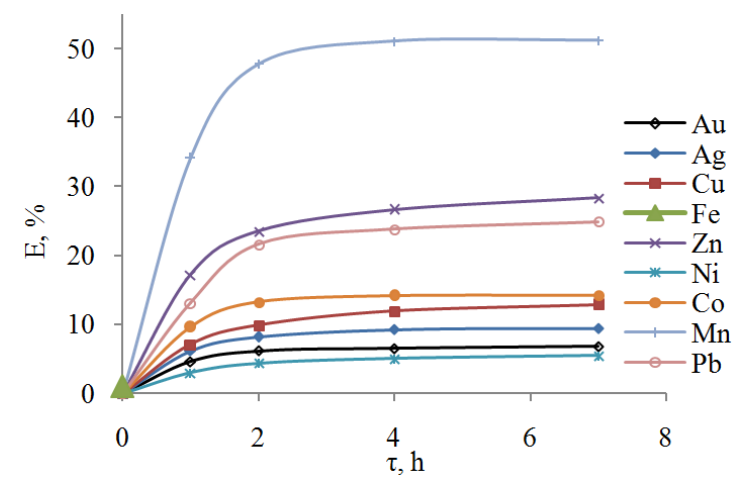

(c)

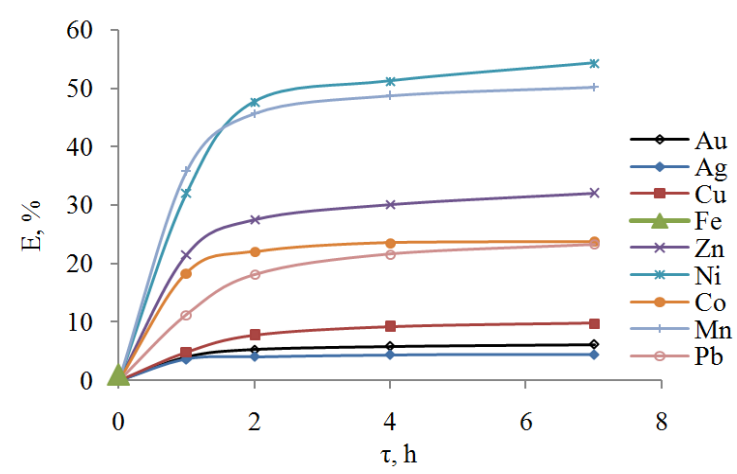

(b)

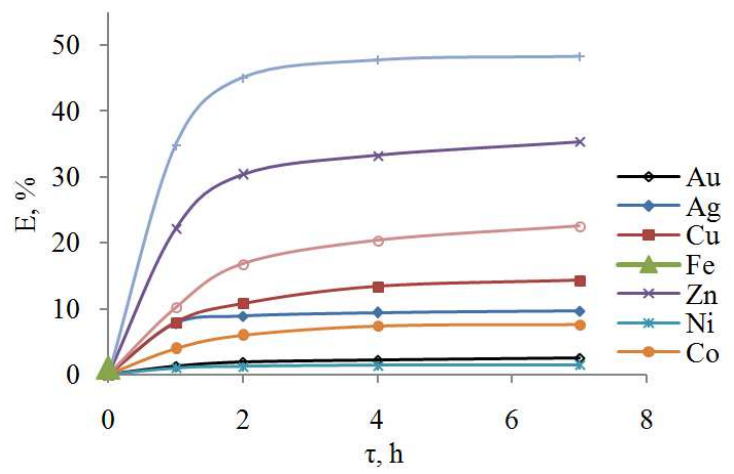

(d)

Fig. 2. (a) AV-16, (b) BNA-1, (c) AM-2B, (d) Purolite A500U/4994, degree of metal sorption extraction from the chemical leaching solution of " $M$ " deposit concentrate 


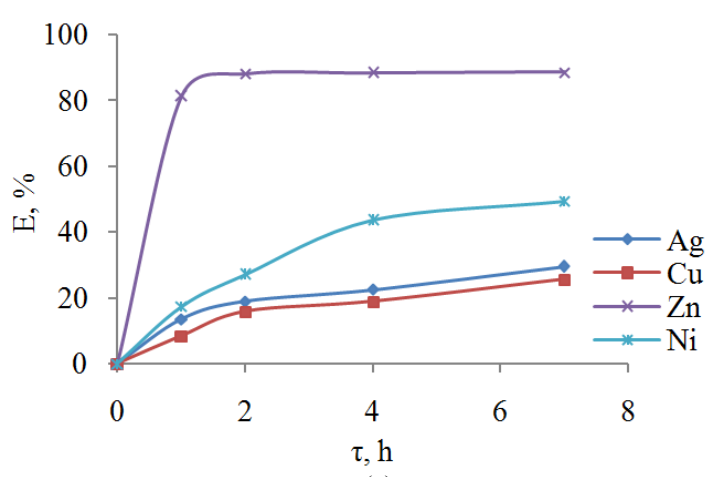

(a)

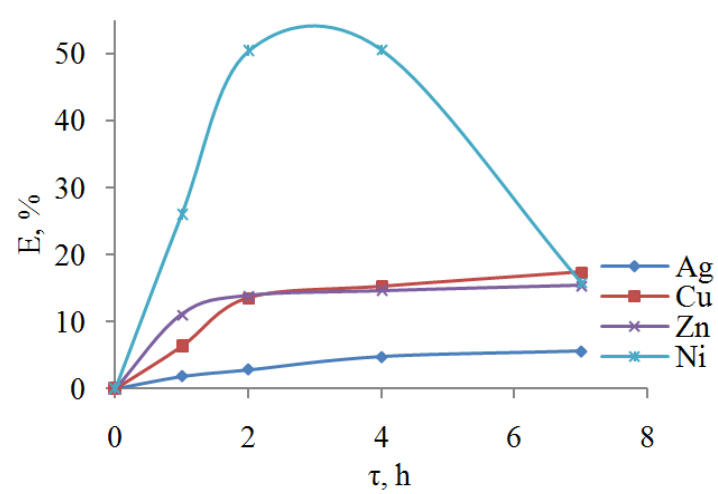

(c)

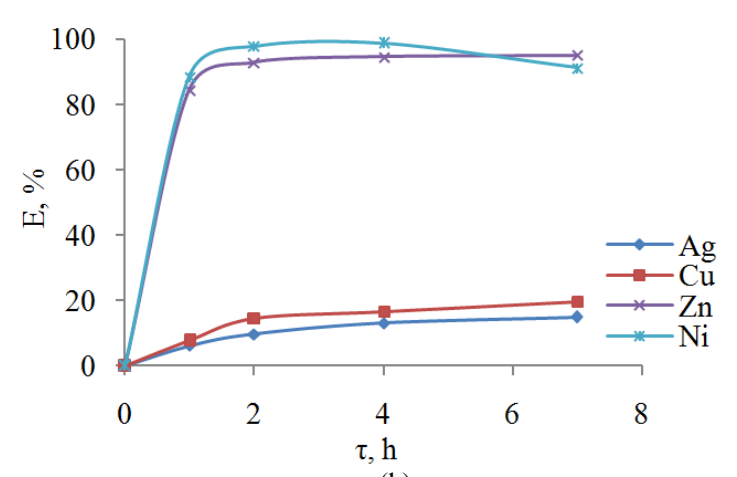

(b)

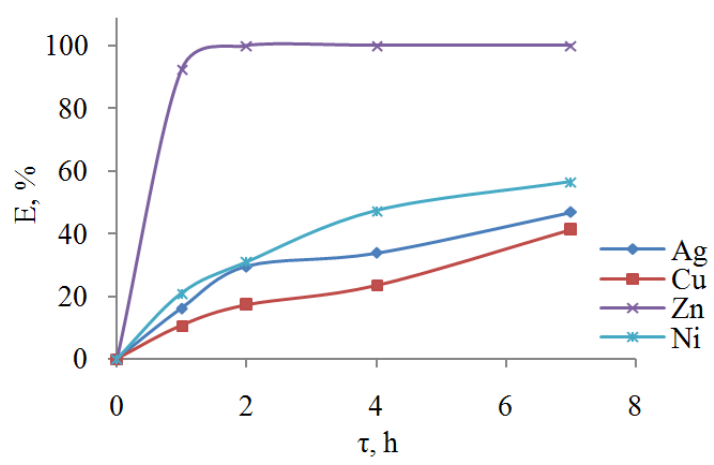

(d)

Fig. 3. (a) AV-16, (b) BNA-1, (c) AM-2B, (d) Purolite A500U/4994, degree of metal sorption extraction from electrochemical leaching solution of " $A$ " deposit concentrate

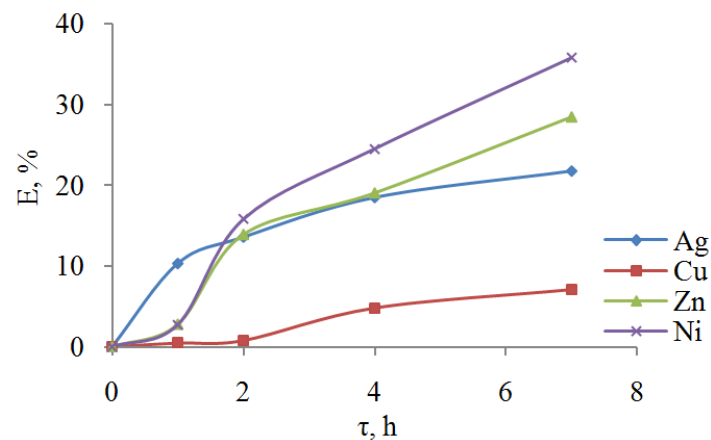

(a)

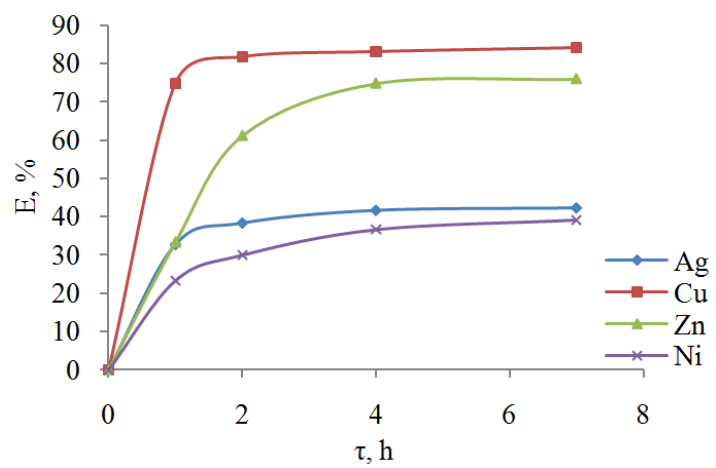

(c)

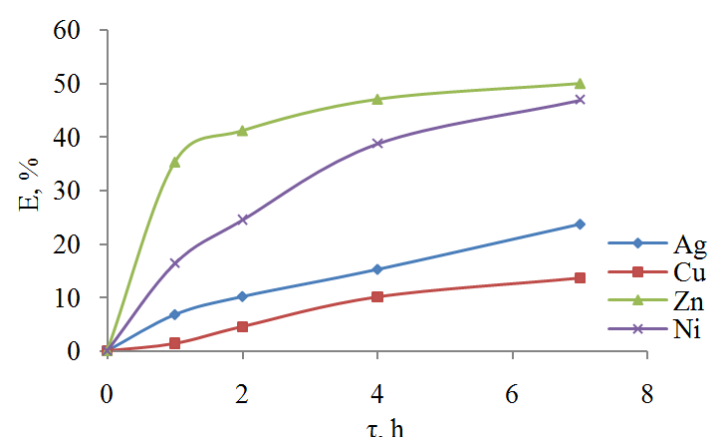

(b)

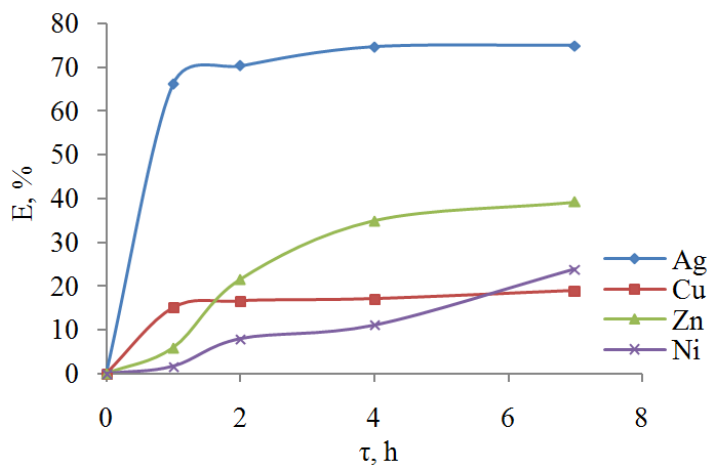

(d)

Fig. 4. (a) AV-16, (b) BNA-1, (c) AM-2B, (d) Purolite A500U/4994, degree of metal sorption extraction from electrochemical leaching solution of " $\mathrm{M}$ " deposit concentrate with anionites 


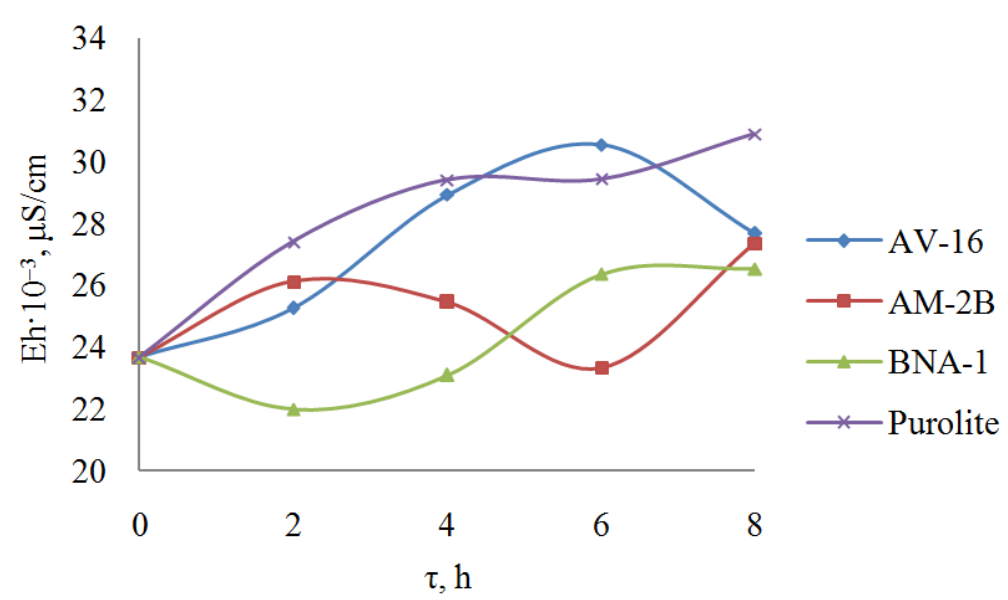

Fig. 5. Conductivity variation in the course of non-ferrous noble metals sorption from leaching process solution

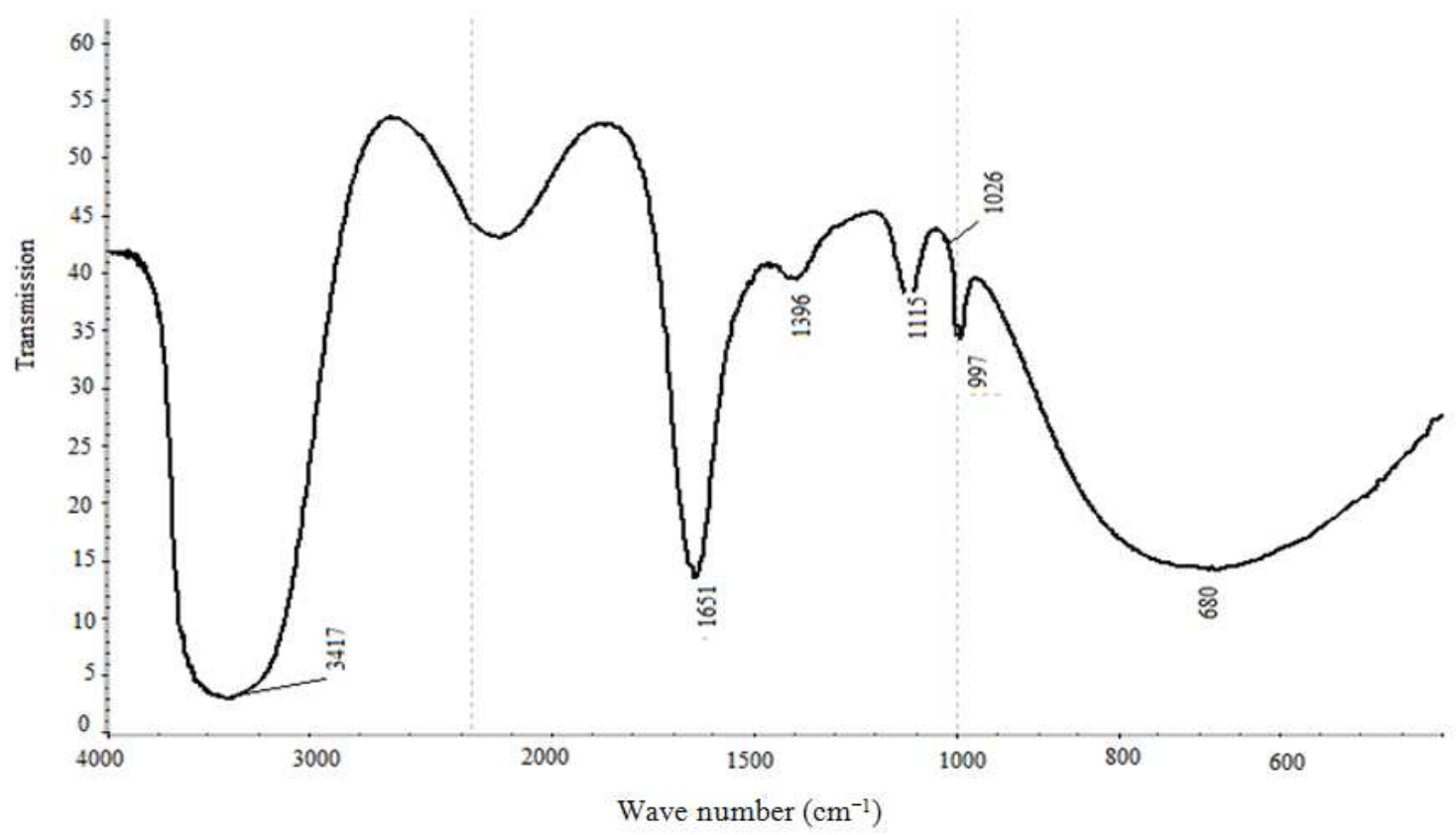

Fig. 6. IR-spectrum of electrochemical leaching process solution of "A" deposit concentrate Y-axis-Transmittance; X-axis-Wave number $\left(\mathrm{cm}^{-1}\right)$

In the course of non-ferrous and noble metals sorption electrical conductivity of solutions was periodically decreasing and increasing with continuous reduction of non-ferrous metals content in the solution (Fig. 5). This is connected both with sorption capacity of anion exchange resins and with variations in the microstructure of the investigated systems.

\section{Compositions of Leaching Solutions}

The results of atomic-absorption analysis of chemical and electrochemical leaching solutions of concentrates from "A" and "M" deposits are given in Table 1 and 2, respectively.

\section{IR-Spectroscopy Research}

$\mathrm{R}$-spectrum of the electrochemical leaching process solution of " $A$ " deposit concentrate is shown in Fig. 6. Absorption valence bands of $v(\mathrm{OH}), 3417$ $\mathrm{cm}^{-1}$, deformational bands of $\delta \mathrm{HOH}, 1651 \mathrm{~cm}^{-1}$ and librational band of $v_{\mathrm{L}} \mathrm{H}_{2} \mathrm{O}, 680 \mathrm{~cm}^{-1}$ of molecular water fluctuations were observed on the IR spectrum. Group $\left[\mathrm{S}_{2} \mathrm{O}_{3}\right]^{2-}$ was $1115,997 \mathrm{~cm}^{-1}$. Group $\left[\mathrm{SO}_{4}\right]^{2-}$ was $1115,1026 \mathrm{~cm}^{-1}$ (Nakamoto, 2009).

Optical density was measured at the maximum of absorption bands that characterize fluctuations $v \mathrm{OH}, \delta$ $\mathrm{HOH}, v_{\mathrm{L}} \mathrm{H}_{2} \mathrm{O}, v_{4}(\mathrm{E})$ of thiosulfate ion, $v_{3}\left(\mathrm{~F}_{2}\right)$ of sulfate ion, $v_{1}\left(\mathrm{~A}_{1}\right)$ of thiosulfate ion and $v_{3}$ of $\left[\mathrm{CO}_{3}\right]^{2-}$ group (Fig. 6). 


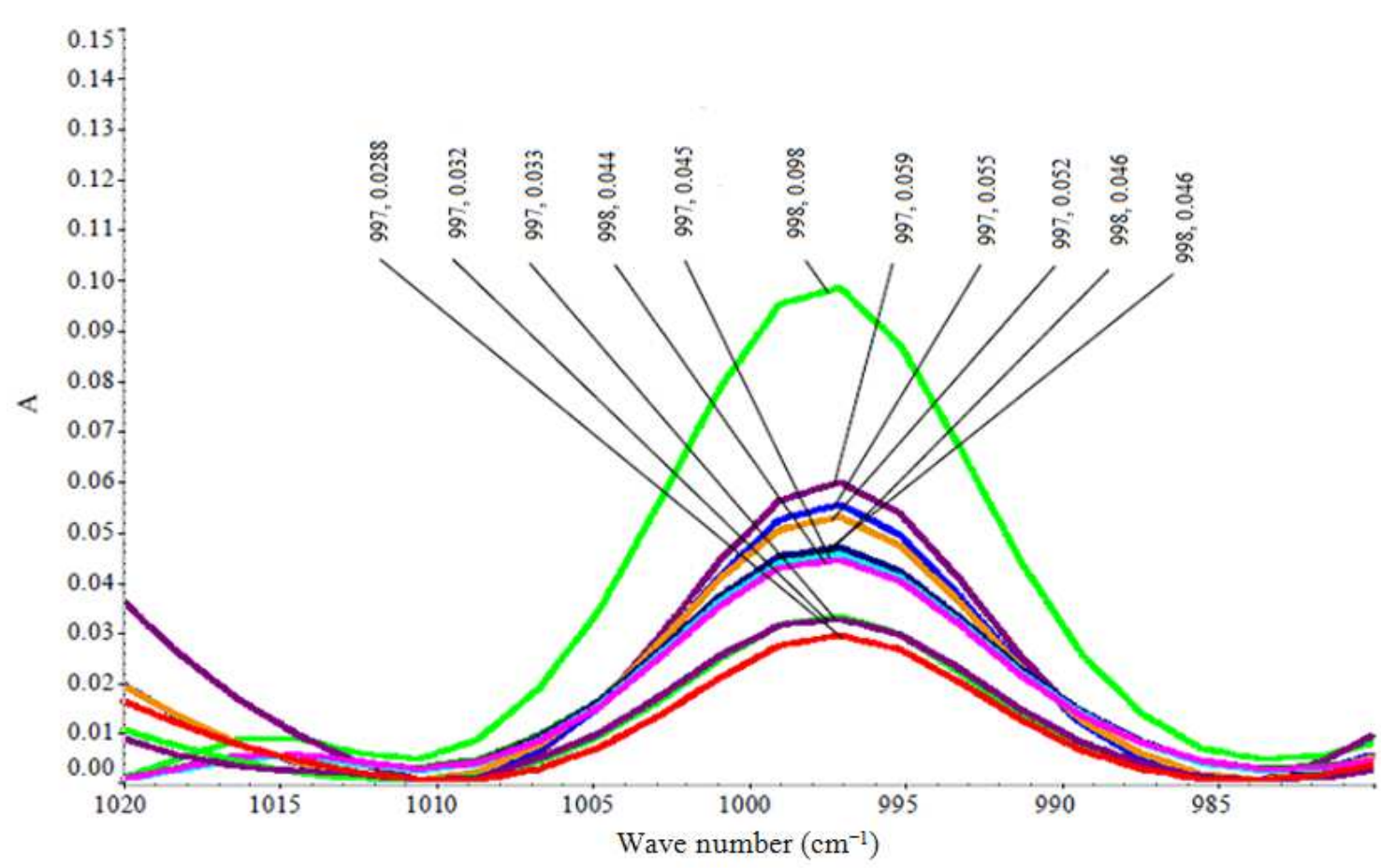

Fig. 7. Correlation between spectral regions of solutions after automatic adjustment of the baseline in the range of $1020-980 \mathrm{~cm}^{-1}$

Table 1. Compositions of chemical leaching process solutions

\begin{tabular}{llllllll}
\hline Solution & $\mathrm{Au}, \mathrm{mg} / \mathrm{dm}^{3}$ & $\mathrm{Ag}, \mathrm{mg} / \mathrm{dm}^{3}$ & $\mathrm{Cu}, \mathrm{mg} / \mathrm{dm}^{3}$ & $\mathrm{Ni}, \mathrm{mg} / \mathrm{dm}^{3}$ & $\mathrm{Co}, \mathrm{mg} / \mathrm{dm}^{3}$ & $\mathrm{Zn}, \mathrm{mg} / \mathrm{dm}^{3}$ & $\mathrm{Mn}, \mathrm{mg} / \mathrm{dm}^{3}$ \\
\hline $\begin{array}{l}\text { Chemical leaching solution of } \\
\text { "A" deposit concentrate }\end{array}$ & - & 9.73 & 154.3 & 1.38 & 0.339 & - & 5.63 \\
$\begin{array}{l}\text { Chemical leaching solution of } \\
\text { "M" deposit concentrate }\end{array}$ & 0.0324 & 8.117 & 185.5 & 1.637 & 0.297 & 5.73 & 9.404 \\
\hline
\end{tabular}

Table 2. Compositions of electrochemical leaching process solutions

\begin{tabular}{lllll}
\hline Solution & $\mathrm{Ag}, \mathrm{mg} / \mathrm{dm}^{3}$ & $\mathrm{Cu}, \mathrm{mg} / \mathrm{dm}^{3}$ & $\mathrm{Zn}, \mathrm{mg} / \mathrm{dm}^{3}$ & $\mathrm{Ni}, \mathrm{mg} / \mathrm{dm}^{3}$ \\
\hline Electrochemical leaching solution of "A" deposit concentrate & 0.0480 & 11.86 & 0.039 & 0.124 \\
Electrochemical leaching solution of "M" deposit concentrate & 0.0613 & 78.80 & 0.530 & 0.490 \\
\hline
\end{tabular}

Figure 7 shows correlation between spectral regions of chemical and electrochemical leaching process solutions before and after metal sorption by anionites upon automatic adjustment of the baseline in the range of $1020-980 \mathrm{~cm}^{-1}$. The figure indicates spectra in the descending order of the intensity of absorption band of $\left[\mathrm{S}_{2} \mathrm{O}_{3}\right]^{2-}$ ion vibration $v_{1}\left(\mathrm{~A}_{1}\right)$. Intensity falloff is observed for $\left[\mathrm{S}_{2} \mathrm{O}_{3}\right]^{2-}$ ion vibration $v_{1}\left(\mathrm{~A}_{1}\right)$ absorption band from chemical and electrochemical leaching process solutions of concentrates to the solutions after sorption of non-ferrous and noble metals.

\section{Discussion}

In Fig. 1 illustrated that in case of using AV-16 anionite $\mathrm{Ni}$ is extracted to a greater extent (55\%) (Fig. 1a), in case of BNA-1copper is primarily extracted (54\%) (Fig. 1b) and Purolite A500U/4994 anionite promoted cobalt extraction (59\%) (Fig. 1d). AM-2B anionite demonstrated the least affinity to ions of metals contained in the chemical leaching solution of " $\mathrm{A}$ " deposit concentrate (Fig. 1c).

In case of BNA-1 anionite sorption degree of all metals increased during the first $2 \mathrm{~h}$ of leaching time and remained the same during next $6 \mathrm{~h}$; in this case iron was not extracted and the extraction degree of other metals did not exceed 53\% (Zn 27\%, Ni 53\%, Cu 8\%, Co 23\%, Zn $30 \%$, Mn 48\%, Pb 23\%, Au 5\% and Ag 4\%) (Fig. 2b).

In both cases maximum extraction was characteristic of zinc (30 and 34\%, respectively) and manganese $(50 \%)$. Extraction of other metals on both anionites did not exceed $23 \%$ over $8 \mathrm{~h}$ of sorption.

Nickel was sorbed by $92 \%$ on anion exchange resins; BNA-1 anionite (Fig. 3b) showed $\mathrm{Ni}$ extraction degree $(92 \%)$. In case of AM-2B anionite $\mathrm{Ni}$ extraction degree achieved $54 \%$ in the first $4 \mathrm{~h}$ of the 
process, but after $4 \mathrm{~h}$ sorption degree fell down to $15 \%$ (Fig. 3c). This is likely to indicate resolution of nickel compounds.

In case of electrochemical leaching solutions of " $M$ " deposit concentrate the degree of metal sorption extraction on AV-16 ion-exchange resin did not exceed $40 \%$ (Fig. 4a), on BNA-1 anionite metals were sorbed at most by $50 \%$ (Fig. $4 \mathrm{~b}$ ). For other anion-exchange resins these values were considerably higher; thus, in case of AM-2B copper was extracted by $84 \%$, zinc-by $76 \%$ (Fig. 4c) and using A500U/4994 silver extraction degree of $75 \%$ was achieved (Fig. 4 d).

Red shift of absorption band maximum value at wave number of $1115 \mathrm{~cm}^{-1}$ by $4 \mathrm{~cm}^{-1}$ relative to the fluctuations of $v_{4}(E)$ of thiosulfate-ion in the $0.1 \mathrm{M}$ test solution of sodium thiosulfate is indicative of the presence of $\left[\mathrm{SO}_{4}\right]^{2-}$ ion in the system (Skoog et al., 2014). The band with maximum at wave number of 1026 $\mathrm{cm}^{-1}$ in the range of manifestations of the stretching vibrations of $\mathrm{S}=\mathrm{O}$ bond shows reduction of symmetry of sulfate group and monodentate coordination of this group [61, 62]. Group $\left[\mathrm{CO}_{3}\right]^{2-}$ was $1396 \mathrm{~cm}^{-1}$.

Optical density at the maximums of absorption bands assigned to water stretching vibrations $v \mathrm{OH}$ amounted to 1.541 ; OD assigned to water deformation vibrations $\delta$ $\mathrm{HOH}$ equaled to 0.871 ; OD assigned to water libration vibrations $v_{\mathrm{L}} \mathrm{H}_{2} \mathrm{O}$ was 0.850 . At the maximum of absorption band characterizing vibration $v_{4}(\mathrm{E})$ of thiosulfate ion, at wave number of $1115 \mathrm{~cm}^{-1}$ optical density made $0.424^{1}$ (Nakamoto, 2009).

Intensity falloff is observed for $\left[\mathrm{S}_{2} \mathrm{O}_{3}\right]^{2-}$ ion vibration $v_{1}\left(A_{1}\right)$ absorption band from chemical and electrochemical leaching process solutions of concentrates to the solutions after sorption of nonferrous and noble metals (Fig. 7).

\section{Conclusion}

This paper presents a study that has been undertaken to investigate sorption behavior of noble and non-ferrous metals from chemical and electrochemical leaching thiosulfate solutions using various anionites. The potential selective sorption extraction of zinc and nickel from electrochemical leaching solutions on BNA-1 anionite was revealed, which will enable to obtain practically complete extraction thereof (up to 99\%) and will contribute to increasing the extraction degree of other valuable components (copper, silver) resulting from concentration reduction of metals, having high affinity to anionite.

Percentage of gold and silver extraction from thiosulfate solutions is much less than the same for cyanide solutions, which is attributable to the specific sorption conditions: High concentration of thiosulfate ions (as well as to the presence of $\mathrm{S}^{2-}, \mathrm{SO}_{4}{ }^{2-}, \mathrm{S}_{4} \mathrm{O}_{6}{ }^{2-}$ and
$\mathrm{SO}_{3}{ }^{2-}$ ions formed as a result of thiosulfate decomposition) and presence of thiosulfate complexes of non-ferrous metals in the system.

It has been demonstrated that depending on the type of the raw material used it is efficient to perform silver and copper sorption from electrochemical leaching solutions with the help of Purolite A500U/4994 and AM$2 \mathrm{~B}$ anion-exchange resins. In case of chemical leaching process solutions, the degree of metal extraction is less, which is connected with more complex chemical composition of these solutions.

It is obvious that the nature of the sorption extraction of metals from process solutions is associated with the microstructure of the solutions, since leaching solutions have quasi-homogeneous structure. This fact is confirmed by the extreme variation of solution conductivity with continuous reduction of metals content in the solution.

\section{Acknowledgment}

The authors gratefully acknowledge the financial support from the Ministry of Education and Science of the Republic of Kazakhstan (№ 496, April 07, 2015).

\section{Author's Contributions}

Bagdaulet Kenzalyevich Kenzhaliyev: Contributed to the reviewing of the article critically.

Renata Ramilevna Iskhakova: Organized the study, data collection of the study sample, analysis and writing of the manuscript.

Zamzagul Duisenovna Dosymbayeva: Designed the research plan, participated in the results analysis.

\section{Ethics}

The authors have no conflicts of interest in the development of the research and publication of this article.

\section{References}

Adams, M.D., 2005. Advances in Gold Ore Processing. 1st Edn., Elsevier, Amsterdam, ISBN-10: 0080459080, pp: 1027.

Akcil, A., C. Erust, C.S. Gahan, M. Ozgun and M. Sahin et al., 2015. Precious metal recovery from waste printed circuit boards using cyanide and non-cyanide lixiviants-a review. Waste Manage., 45: 258-271. DOI: 10.1016/j.wasman.2015.01.017

Aktas, S. and M.H. Morcali, 2011. Gold uptake from dilute chloride solutions by a Lewatit TP 214 and activated rice husk. Int. J. Min. Proc., 101: 63-70. DOI: 10.1016/j.minpro.2011.07.007

Bringas, J.E. and M.L. Wayman, 1998. The Metals Red Book: Nonferrous Metals. 2nd Edn., CASTI Pub., Edmonton, ISBN-10: 1894038096, pp: 476. 
Xia, C., 2008. Associated Sulfide Minerals in Thiosulfate Leaching of Gold: Problems and Solutions. PhD Thesis, Queen's University, Kingston, Ontario, Canada.

Choi, Y., P. Kondos, M.G. Aylmore, J. McMullen and G. van Weert, 2009. Thiosulfate generation in situ in precious metal recovery.

Conić, V.T., M.M.R. Vujasinović, V.K. Trujić and V.B. Cvetkovski, 2014. Copper, zinc and iron bioleaching from polymetallic sulphide concentrate. Trans. Nonferrous Metals Society China, 24: 3688-3695. DOI: $10.1016 / \mathrm{S} 1003-6326(14) 63516-0$

Dubeck, M. and S.J. Im, 1976. Leaching of low-grade nickel complex ore.

Fotoohi, B. and L. Mercier, 2015. Recovery of precious metals from ammoniacal thiosulfate solutions by hybrid mesoporous silica: 3-Effect of contaminants. Separat. Purificat. Technol., 139: 14-24.

DOI: 10.1016/j.seppur.2014.10.019

Grosse, A.C., G.W. Dicinoski, M.J. Shaw and P.R. Haddad, 2003. Leaching and recovery of gold using ammoniacal thiosulfate leach liquors (a review). Hydrometallurgy, 692: 1-21.

DOI: $10.1016 / \mathrm{S} 0304-386 \mathrm{X}(02) 00169-\mathrm{X}$

Harvey, T.J., W.T. Yen and J.G. Paterson, 1992. Selective zinc extraction from complex copper/zinc sulphide concentrates by pressure oxidation. Miner. Eng., 9: 975-992. DOI: 10.1016/0892-6875(92)90125-S

Kenzhaliev, B., 2014. Electrochemical method for extracting non-ferrous and precious metals from refractory materials using combined reactions. Proceedings of the 15th Topical Meeting of the International Society of Electrochemistry, (ISE' 14), Interfacial Electrochemistry at Atomic, Molecular and Nanoscale Domains, Niagara Falls, Canada.

Kenzhaliev, B.K., A.N. Berkinbayeva and E.N. Suleimenov, 2014. Using sulfur graphite electrode for extracting metals from refractory materials. Proceedings of the 65th Annual Meeting of the International Society of Electrochemistry Ubiquitous Electrochemistry, (EUE' 14), Lausanne, Switzerland.

Kononova, O.N., A.G. Kholmogorov, N.V. Danilenko, N.G. Goryaeva and K.A. Shatnykh et al., 2007. Recovery of silver from thiosulfate and thiocyanate leach solutions by adsorption on anion exchange resins and activated carbon. Hydrometallurgy, 1-4: 189-195.

DOI: $10.1016 /$ j.hydromet.2007.03.012

Kononova, O.N., M.A. Kuznetsova, A.M. Melnikov, N.S. Karplyakova and Y.S. Kononov, 2014. Sorption recovery of copper (II) and zinc (II) from chloride aqueous solutions. J. Serb. Chem. Soc., 79: 1037-1049. DOI: 10.2298/JSC130911033K
Kyle, J.H., P.L. Breuer, K.G. Bunney and R. Pleysier, 2012. Review of trace toxic elements $(\mathrm{Pb}, \mathrm{Cd}, \mathrm{Hg}$, $\mathrm{As}, \mathrm{Sb}, \mathrm{Bi}, \mathrm{Se}, \mathrm{Te}$ ) and their deportment in gold processing. Hydrometallurgy, 111-112: 10-21. DOI: $10.1016 /$ j.hydromet.2011.09.005

Laatikainen, M. and E. Paatero, 2005. Gold recovery from chloride solutions with XAD-7: Competitive adsorption of Fe(III) and Te(IV). Hydrometallurgy, 3-4: 154-171. DOI: 10.1016/j.hydromet.2005.06.005

Lampinen, M., A. Laari and I. Turunen, 2015. Ammoniacal thiosulfate leaching of pressure oxidized sulfide gold concentrate with low reagent consumption. Hydrometallurgy, 151: 1-9.

DOI: $10.1016 /$ j.hydromet.2014.10.014

Li, J., M.S. Safarzadeh, M.S. Moats, J.D. Miller and K.M. LeVier et al., 2012. Thiocyanate hydrometallurgy for the recovery of gold. Part IV: Solvent extraction of gold with Alamine 336. Hydrometallurgy, 113-144: 25-30. DOI: $10.1016 /$ j.hydromet.2011.11.006

Lorenzen, L. and J.S.J. Van Deventer, 2003. The mechanism of leaching of gold from refractory ores. Miner. Eng., 10-12: 1377-1387. DOI: 10.1016/0892-6875(92)90173-7

Luo, X.P., Q. Yan and H.Q. Peng, 2006. Solvent extraction of gold from polysulfide solution. Hydrometallurgy, 3-4: 144-149. DOI: 10.1016/j.hydromet.2006.03.015

Mohammadnejad, S., J.L. Provis and J.S.J. van Deventer, 2011. Gold sorption by silicates in acidic and alkaline chloride media. Int. J. Mineral Process., 100: 149-156. DOI: 10.1016/j.minpro.2011.05.013

Nakamoto, K., 2009. Infrared and Raman Spectra of Inorganic and Coordination Compounds, Applications in Coordination, Organometallic and Bioinorganic Chemistry. 6th Edn., John Wiley and Sons, Hoboken, N.J., ISBN-10: 0470405872, pp: 400.

Petersen, J. and C. Muzawazi, 2014. Base metal heap and tank leaching of a platreef flotation concentrate using ammoniacal solutions.

Skoog, D.A., D.M. West, F.J. Holler and S.R. Crouch, 2014. Fundamentals of analytical chemistry. Chem. Listy, 108: 694696.

Su, Y.H., 2012. Noble Metals. 1st Edn., Intech, pp: 416.

Syed, S., 2012. Recovery of gold from secondary sources-a review. Hydrometallurgy, 115-116: 30-51. DOI: 10.1016/j.hydromet.2011.12.012

Tran, T. and A. Davis, 1992. Extraction of gold in halide media. Extract Met Gold and Base Metals.

Lalancette, J.M., H. Menard and R. Zamojska, 1999. Process for removing and recovering copper, silver and zinc from sulfide ores. Ug Plus International Inc. Lalancette.

Zhang, H. and D. Dreisinger, 2003. Gold recovery from thiosulfate leaching. The University of British Columbia. 
Vignes, A., 2013. Extractive Metallurgy 3: Processing Operations and Routes. 1st Edn., John Wiley and Sons, London, ISBN-10: 1118617029, pp: 377.

Wan, R., K.M. LeVier and R.B. Clayton, 1995. Hydrometallurgical process for the recovery of precious metal values from precious metal ores with thiosulfate lixiviant. Miner. Eng.

DOI: 10.1016/0892-6875(95)93592-M

Wan, R.Y., 1997. Importance of solution chemistry for thiosulfate leaching of gold. The Australasian Institute of Mining and Metallurgy, Carlton, Vic.
West-Sells, P.G. and R.P. Hackl, 2005. A novel thiosulfate leach process for the treatment of carbonaceous gold ores. Treatment of Gold Ores, CIM, Alberta.

Yuce, A.E., 1994. Thiourea: An alternative lixiviant for gold and silver extraction. 